The Journal of Animal \& Plant Sciences, 31(1): 2021, Page: 46-52

ISSN (print): 1018-7081; ISSN (online): 2309-8694

\title{
EFFECTS OF MONOCHROMATIC LIGHT ON PERFORMANCE, EGG QUALITY, YOLK CHOLESTEROL AND BLOOD BIOCHEMICAL PROFILE OF LAYING HENS
}

\author{
F. Yenilmez ${ }^{1 *}$, A. Atay ${ }^{2}$, U. Serbester ${ }^{3}$ and L. Celik ${ }^{3}$ \\ ${ }^{1}$ Cukurova University, Vocational School of Tufanbeyli, Turkey \\ ${ }^{2}$ Hakkari University, Vocational School of Colemerik, Colemerik, Turkey \\ ${ }^{3}$ Cukurova University, Agriculture Faculty, Department of Animal Science, Turkey \\ ${ }^{*}$ Corresponding author's e-mail: fyenilmez@cu.edu.tr
}

\begin{abstract}
The present study was conducted to investigate whether monochromatic light affects the production performance, egg quality and some plasma parameters of layers. In this study, white and green fluorescent lamps were used to illuminate Brown-Nick hens for 8 weeks. Light sources made uniform to a light intensity of 15 lx. Forty-seven-week-old layers were divided into 2 groups of similar mean weight comprising 16 birds each and housed in individual cages. A 16:8 hours light:dark photoperiod was employed. The layers were exposed to conventional ambient temperature and 50-60\% relative humidity for $24 \mathrm{~h}$ per day. Performance was evaluated by recording feed intake, egg weight and egg production on daily basis; egg quality and egg cholesterol level on weekly basis; and blood parameters on $56^{\text {th }}$ day of the experiment. The results indicated that green light application did not have any significant effect on feed intake, feed conversion ratio, egg production, total number of eggs, total egg weight, average egg weight, cholesterol level of egg yolk and egg quality of laying hens. However, green light application affected egg yolk color $\mathrm{a}^{*}$ and $\mathrm{b}^{*}$ values, but decreased serum albumin concentration. The results suggest that green light application may improve the yolk color of laying hens.
\end{abstract}

Keywords: Light color, egg cholesterol, egg quality, Brown-Nick hen, serum parameters.

https://doi.org/10.36899/JAPS.2021.1.0191

Published online August 26, 2020

\section{INTRODUCTION}

Light is effective for controlling physiological and behavioral processes that influence egg production and egg quality of laying hens. The chicken eye is superior to the eyes of other livestock, has the ability to see light wavelength $(380-760 \mathrm{~nm})$ in a narrow range and can discriminate light color (Prescott and Wathes, 1999). Apart from the eyes, the extra-retinal photoreceptors, located in the hypothalamus and in other sites of the brain, are involved in transduction of photo stimulation (Rozenboim et al. 1998). Previous studies show that the effects of monochromatic light on egg production and egg quality of laying hens are different. Li et al. (2019) reported that layer pullets preferred blue light the most compared with white, green and red lights. Similarly, in another study light color influenced egg production (Hassan et al. 2013). Mudhar and Tabeekh (2016) also demonstrated blue light increased FSH but red light increased LH hormone in laying hens. Zhang et al. (2017) suggested that breeders exposed to light of 740 $\mathrm{nm}$ improved performance of laying hens. Lewis et al. (2007) reported that pullets mature much earlier under light of short wavelength than under long wavelength light. Er et al. (2007) reported that egg weight was decreased significantly in hens that underwent red monochromatic light treatment, while eggshell quality improved under green light treatment. Kim et al. (2010) claimed that red LED light causes improvement in eggshell thickness. On the other hand, it has been shown that monochromatic lights are not efficient in laying hens. Rozenboim et al. (1998) and Lewis et al. (2007) observed that light treatment did not affect the performance, egg production and egg quality of laying hens. Groot (2018) presented that different light spectra did not affect behavior of laying hens. Li et al. (2015) showed that monochromatic light did not affect the melatonin receptors in laying hens. Use of white or red LEDs did not cause any negative effect on egg production of laying hens (Borille et al., 2013). Borille et al. (2015) demonstrated that the use of different colors of LED light in the rearing environment of laying hens in the second cycle did not affect egg production and quality.

Research on the effect of various light colors on broiler chicks have been also conducted previously. It has been demonstrated that blue and green lights improved growth performance and immune system (Cao et al., 2008; Sultana et al., 2013). Astuti et al. (2015) observed that body weights were increased under blue light treatment without adversely affecting stress indicators. Similarly, Fayoumi chickens maintained under blue light feel better welfare than exposed to yellow, red, green lights (Hesham et al., 2018). Green monochromatic LED resulted in higher body weight marketed up to 7 or 5 
week of age male or female respectively (Guevara et al., 2015). Whereas Leigh et al., (2017) reported that broiler performance was similar under white, green, blue, red LED lights.

Studies regarding the effects of monochromatic light on egg quality, egg cholesterol and blood biochemistry of laying hens are still contradictory. For this reason, the purpose of this study is to investigate the effects of monochromatic light on egg production, egg quality, egg cholesterol levels and some plasma metabolites of laying hens.

\section{MATERIALS AND METHODS}

The present study was carried out in the February-March period of 2014, in the Layer Chicken Trial Unit of the Department of Animal Science, Faculty of Agriculture, University of Cukurova, Adana, Turkey. Prior to the study, thirty-two 47-week-old Brown-Nick layers were fed ad libitum with a standard layer diet for a week, egg production and egg weight were recorded daily. When the birds were 48 weeks old, they were divided into 2 experimental groups of similar mean body weight (1880 vs $1869 \mathrm{gm}$ ) and laying performance (egg weight 60.81 vs $60.62 \mathrm{gm}$; egg number 5.81 vs 5.86), comprising 16 birds each. During the experiment, two light regimes were employed in two experimental rooms, which were identical but different in environmental light color. The birds were housed in individual layer cages $(40 \times 40 \times 40 \mathrm{~cm})$ of three-tier battery blocks in a completely randomized design at a conventional ambient temperature $\left(20-24^{\circ} \mathrm{C}\right)$ with a relative humidity of 50$60 \%$. White $(400-760 \mathrm{~nm})$ and green $(560 \mathrm{~nm})$ fluorescent lamps (36 W) were used to illuminate BrownNick hens for 8 weeks (48-56 wk). Lamps were installed on the ceiling and side walls to achieve an average of 15 $\mathrm{lx}$ of light. The light intensity was measured with a luxmeter and light sources were equalized at the light intensity of 15 lx. A 16:8 hours light:dark photoperiod was employed. Light was supplied 16 hours (from 05:00 to 21:00) each day. The birds were fed a standard layer diet $(17.8 \% \mathrm{CP} ; 2650 \mathrm{kcal} / \mathrm{kg} \mathrm{ME})$ obtained from a commercial feed industry. The experimental procedure was approved by the Animal Care and Ethic Committee of Cukurova University, Adana, Turkey. The performance of layers was determined by measuring the feed intake, egg mass, feed conversion ratio (egg mass:feed intake) and egg production (in house, number and weight) on a daily basis. The egg-shape index (width/length), egg weight, shell weight, shell thickness, yolk weight, albumen weight, albumen height, yolk index (weigh/height) and yolk color score L (lightness), $\mathrm{a}^{*}$ (redness), $\mathrm{b}^{*}$ (yellowness) (Hunter Lab) of each egg obtained on the third day of every week were calculated for egg quality parameters (32 eggs). Shell samples were taken from the top, middle and bottom of the eggs, shell membranes extracted and the thickness of the shell was measured with a micrometer. The means of shell were calculated from recorded data before the statistical analysis.

Five birds from each group were randomly chosen, and blood samples were collected by puncture of the vena brachialis biweekly throughout the experiment. After centrifugation $\left(1500 \mathrm{rpm}, 5\right.$ minutes, $\left.4^{\circ} \mathrm{C}\right)$, serums were carefully harvested and stored at $-20^{\circ} \mathrm{C}$ until analysis. The serum concentrations of AST (Aspartat aminotransferaz), ALT (Alanin aminotransferaz), total protein, total cholesterol, albumin and globulin were measured with commercial kits on an automated KEYLAB LiquiVet Analyzer. The egg yolk cholesterol (6 eggs from each group) content (Boehringer Manheim GmbH Biochemica 1995) was determined weekly using eggs from hens used for the blood biochemistry analysis with a specific kit. The egg yolks were hard-boiled for 10 minutes, homogenized and divided into $0.1 \mathrm{~g}$ yolk fractions. After lipid extraction with isopropanol (4 mL, incubation at $37^{\circ} \mathrm{C}$ for 10 minutes and centrifugation at $3000 \mathrm{rpm}$ for 5 minutes at $37^{\circ} \mathrm{C}$ ), and the yolk cholesterol concentration was determined in the filtered samples by UV spectrophotometer by using commercial kits and calculated by the method of Boehringer Mannheim $\mathrm{GmbH}$ Biochemica.

Statistical data processing was performed using the software program SAS/STAT (SAS Institute, 2000). Statistical parameters were expressed as the arithmetic mean (x), and standard error (SE). Testing of significance of differences for the performance, quality of eggs and some blood parameters originating from two laying hens keeping lighting systems was carried out by using the ttest for independent samples. Significance of means was accepted at $\mathrm{P} \leq 0.05$.

\section{RESULTS AND DISCUSSION}

The effects of monochromatic light on performance, egg quality and some serum parameters of laying hens are summarized in Table 1, 2 and 3 respectively.

The results show that green light application did not have any significant $(\mathrm{P}>0.05)$ effect on feed intake, feed conversion ratio, egg production, total number of eggs, total egg weight, average egg weight, egg yolk cholesterol level, serum ALT, AST, total cholesterol, total protein and globulin concentration of laying hens. However, green light application affected egg yolk color $\mathrm{a}^{*}(\mathrm{P} \leq 0.01)$ and $\mathrm{b}^{*}$ values $(\mathrm{P} \leq 0.05)$, so that the yolk has become darker but decreased serum albumin concentration $(\mathrm{P} \leq 0.05)$.

Literature on the effect of light color on laying hens performance, egg quality and blood characteristics are very limited. In the study of Hassan et al. (2013, 2014) red and green light combination treatment 
improved feed intake and feed conversion ratio in laying hens. Riber (2015) observed that final live body weight and the yield from the breast muscle tenders were increased in cold white $(6,065 \mathrm{~K})$ color temperature compared to neutral white $(4,100 \mathrm{~K})$ color temperature. Ke et al. (2011) determined a higher body weight in broilers illuminated with blue LED light compared to with red, green and blue LED lights. Rozenboim et al. (1999) reported that green light stimulate growth at early age, whereas blue light stimulate growth in older birds. Rozenboim et al. (2014) also suggest that shifting birds to a different light environment at 10 or 20 day of age might further stimulate growth. Light wavelength is very important factor in regulating development of sexual organ and laying performance in breeders exposed to light of $740 \mathrm{~nm}$ had better performance in egg laying (Zhang et al., 2017). However, according to some authors (Lewis et al., 2007; Gongruttananun, 2011), there is no differences in laying performance parameters. HuberEicher et al. (2013) indicated that in laying hens the light color did not affect the body weight gain, feed consumption and age at first lay but red light showed better early laying performance. According to Borille et al. (2013) the effect of light sources or period on feed intake is associated to birds had the same visual sensitivity to all tested light sources, and did not change their feeding behavior as a function of light source. Similarly, we did not find any significant differences of performance under green light when compared with control group (white light). Inconsistent responses of poultry to expose to light may be related mainly to interstrains differences, age, sex, different light combinations, duration of time exposed to the light.

The monochromatic light effects on the egg quality results in poultry are still contradictory. Egg weight (Rozenboim et al., 1998; Svobodová et al., 2015), eggshell breaking strength, albumin height, haugh unit and yolk color (Hassan et al., 2013) were not influenced by either the monochromatic or the combined light color. On the other hand red light produces smaller eggs, while the white light makes possible to produce large eggs $(\mathrm{Er}$ et al., 2007). Egg weight has already tended to increase numerically under green light when compared with white light in the current study.

Yang et al. (2016) showed that red light has expedited sexual maturation and promotes egg production in birds. Birds maintained under green light produced fewer eggs and better egg quality than exposed to white, red and blue lights (Li et al., 2014). The eggshell quality in green light was better than those in white, red and blue lights (Er et al., 2007; Hassan et al., 2014; Li et al., 2014). Er et al., (2007) determined a higher color interactions in laying hens reared under white light compared to those reared under blue, green and red light. Our results indicated that egg yolk color $\mathrm{a}^{*}$ and $\mathrm{b}^{*}$ values increased significantly in hens that underwent green light treatment. Yolk color primarily depends on the intake of plant pigment in diet (Long et al., 2014). Carotenoids contain large numbers of double bonds in their molecules, and as a result, they may oxidize, depending on storage time, room temperature and the effect of lighting (Barbosa et al., 2011). Harvesting, milling, extruding, and separating to the flour fraction of corn can result in total carotenoid loss (Ortiz et al., 2018). And these loses can decrease the absorption and deposition of carotenoids by birds in egg yolk (Moreno et al., 2016).

Our results show that yolk color $\mathrm{a}^{*}$ and $\mathrm{b}^{*}$ values increased under green light treatment, possibly due to the improvement in absorption and deposition of carotenoids or the higher pigment contents in the green light spectra during the rearing period. The other possible reason might be that green light treatment enhanced some pigment synthesis in yolk. In addition, light influences formation and isomerization of carotenoids which is cistrans isomerization leads to a decrease of color intensity (Schieber and Carle, 2005). Probably, the cis-trans isomerization increase in yolk color when exposed to green light in laying hens. However, the modes of action of the green light color on the egg quality are still unclear. The effect of light color on the lipid response is poorly understood. Ibrahim et al. (2012) founded that green light group had significantly higher cholesterol level than birds exposed to yellow light color. Firouzi et al. (2014) also demonstrated that blue light decreased serum glucose, cholesterol and triglyceride levels and created a calming effect on birds. Elevated serum glucose, cholesterol and triglyceride levels are as indicators of stress (Thaxton and Puvadolpirod, 2000). In the present study, exposure to green light color did not affect both egg yolk and serum cholesterol levels. The level of serum cholesterol tended to increase numerically while yolk cholesterol level tended to decrease numerically in laying hens housed in green light.

AST, ALT metabolites provide information about the functional capacity of liver that are involved in a particular metabolic pathway. AST is the most sensitive indicator of liver disease in birds (Speer, 2015). Damage of liver causes the release of AST or ALT enzymes into the bloodstream. Hassan et al. (2016) mentioned that monochromatic lights on broiler chicks did not alter liver enzymes (AST and ALT) in a healthy flock. Olanrewaju et al. (2015) mentioned that using two color temperatures of LED light bulbs did not influence plasma AST and ALT concentrations in broiler. In our results, green light color did not affect plasma AST (165 vs. 127), ALT (41.60 vs. 24.20) content but there is a numerical decrease when exposed to green light in laying hens. This numerical improvement is probably due to the relaxing caused by green light on laying hens.

As known that albumin is the main constituent of total protein which is made specifically by the liver (McDonald et al., 2011). In chronic liver disease or 
nephrotic syndrome are decreased albumin levels. Low albumin levels can also be seen in inflammation, shock, and malnutrition. Albumin acts as the main reservoir of the protein and plays a role in colloidal osmotic pressure and acid-base balance; it acts as a carrier for small molecules such as vitamins, minerals, hormones and fatty acids (Wu, 2017). Serum albumin concentrations are indicators of the protein status of the blood. The results of this study show that serum albumin is significantly reduced in chickens grown under green light compared to chickens grown under white light. Smith (1978) suggested that serum albumin is the major protein reserve of the laying hen, which is degraded in response to the needs of protein synthesis in the oviduct. Stress causes hypoalbuminemia in animals. A reduction of plasma albumin concentration can be consequence of reducing albumin synthesis in liver (Ruot et al., 2000). Decreased serum albumin concentration was observed in this study. Total protein and globulin levels decreased numerically in laying hens exposed to green light. Serum total protein and albumin of broilers under Blue-Green mix light, globulin under Green Light and uric acid under Blue Light and triglyceride under Green Light have improved (Abu Tabeekh and Mudhar, 2016). Firouzi et al. (2014) found differences in total serum protein concentration between broilers exposed to yellow monochromatic light and those exposed to blue and red lights. However, they did not make any comments on the result. The data concerning the effect of green light are still contradictory.

Table 1. Effects of monochromatic light on productive performance.

\begin{tabular}{|c|c|c|c|}
\hline Parameters & $\begin{array}{l}\text { White Light } \\
(\text { mean } \pm \text { SE) }\end{array}$ & $\begin{array}{c}\text { Green Light } \\
(\text { mean } \pm \text { SE) }\end{array}$ & $\mathbf{T}^{¥}$ \\
\hline Initial Body Weight (g) & $1880.63 \pm 40.55$ & $1869.69 \pm 44.48$ & 0.8570 \\
\hline Final Body Weight (g) & $1853.75 \pm 43.55$ & $1806.88 \pm 46.36$ & 0.4669 \\
\hline Total Feed Intake (FI; g/bird/56 days) & $6451.25 \pm 91.64$ & $6390.50 \pm 96.94$ & 0.6521 \\
\hline Egg Mass (EM; g/bird/56 days) & $3184.86 \pm 56.31$ & $3214.07 \pm 61.93$ & 0.7296 \\
\hline Feed Conversion Ratio (FI/EM) & $2.03 \pm 0.04$ & $2.00 \pm 0.04$ & 0.4986 \\
\hline Mean Egg Weight (g/day) & $61.64 \pm 0.73$ & $62.41 \pm 0.81$ & 0.4854 \\
\hline Number of Eggs (bird/56 days) & $52.38 \pm 0.48$ & $52.06 \pm 0.67$ & 0.7069 \\
\hline
\end{tabular}

${ }^{\ddagger}$ : Mean values were significantly different at $\mathrm{p} \leq 0.01$ and $\mathrm{p} \leq 0.05$.

SE: Standard error

Table 2. Effects of monochromatic light on egg quality traits.

\begin{tabular}{|c|c|c|c|}
\hline Parameters & $\begin{array}{c}\text { White Light } \\
\text { (mean } \pm \text { SE) }\end{array}$ & $\begin{array}{c}\text { Green Light } \\
(\text { mean } \pm \text { SE) }\end{array}$ & $\mathbf{T}^{¥}$ \\
\hline Egg Weight (g/egg) & $56.87 \pm 1.01$ & $57.67 \pm 1.04$ & 0.7291 \\
\hline Shell Weight (g/egg) & $7.04 \pm 0.09$ & $7.22 \pm 0.07$ & 0.1397 \\
\hline Yolk Weight (g/egg) & $15.78 \pm 0.28$ & $16.30 \pm 0.36$ & 0.2637 \\
\hline Albumen Weight (g/egg) & $34.05 \pm 1.09$ & $34.15 \pm 1.05$ & 0.9481 \\
\hline Shape Index (\%) & $76.64 \pm 0.58$ & $78.05 \pm 0.56$ & 0.0907 \\
\hline Egg Yolk Index & $46.44 \pm 0.36$ & $45.81 \pm 0.26$ & 0.1712 \\
\hline Albumen Index & $8.04 \pm 0.44$ & $7.76 \pm 0.28$ & 0.5985 \\
\hline L (lightness) & $59.20 \pm 0.27$ & $59.36 \pm 0.34$ & 0.7133 \\
\hline a (redness) & $10.44 \pm 0.15$ & $11.33 \pm 0.14$ & 0.0001 \\
\hline b (yellowness) & $56.82 \pm 0.59$ & $58.55 \pm 0.53$ & 0.0370 \\
\hline Haugh Unit & $80.99 \pm 1.56$ & $80.34 \pm 1.35$ & 0.7532 \\
\hline Breaking Strength $\left(\mathrm{kg} / \mathrm{cm}^{2}\right)$ & $4.59 \pm 0.17$ & $4.86 \pm 0.15$ & 0.2351 \\
\hline Mean Shell Thickness ( $\mu \mathrm{m})$ & $374.53 \pm 3.97$ & $378.99 \pm 3.97$ & 0.3771 \\
\hline Egg Yolk Cholesterol Content (mg/g egg) & $19.057 \pm 0.24$ & $18.709 \pm 0.07$ & 0.2348 \\
\hline
\end{tabular}

: Mean values were significantly different at $\mathrm{p} \leq 0.01$ and $\mathrm{p} \leq 0.05$.

SE: Standard error 
Table 3. Effects of monochromatic light on some serum parameters in laying hens.

\begin{tabular}{lccc}
\hline Serum Parameters & $\begin{array}{c}\text { White Light } \\
\text { (mean } \pm \text { SE) }\end{array}$ & $\begin{array}{c}\text { Green Light } \\
\text { (mean } \pm \text { SE) }\end{array}$ & T $^{¥}$ \\
\hline Alanine Aminotransferase, ALT (U/L) & $41.60 \pm 9.37$ & $24.20 \pm 8.44$ & 0.849 \\
Aspartate Aminotransferase, AST (U/L) & $165.33 \pm 17.07$ & $127.71 \pm 20.58$ & 0.844 \\
Total Cholesterol (mg/dL) & $106.80 \pm 10.13$ & $118.86 \pm 13.98$ & 0.668 \\
Total Protein (mg/dL) & $5.13 \pm 0.27$ & $3.98 \pm 0.35$ & 0.769 \\
Albumin (mg/dL) & $1.50 \pm 0.08$ & $1.22 \pm 0.04$ & $\mathbf{0 . 0 3 2}$ \\
Globulin (mg/dL) & $3.63 \pm 0.20$ & $2.76 \pm 0.33$ & 0.388 \\
\hline
\end{tabular}

: Mean values were significantly different at $p \leq 0.01$ and $p \leq 0.05$. SE: Standard error

Conclusion: In conclusion, green light color did not influence laying performance and egg quality except egg yolk pigmentation. Green light application increased egg yolk color $\mathrm{a}^{*}$ and $\mathrm{b}^{*}$ values, but decreased serum albumin concentration. The results suggest that green light application has the potential to increase egg quality in terms of yolk pigmentation.

Acknowledgements: The authors are grateful to Cukurova University Research Fund (TMYO2013-483) for their financial supports.

\section{REFERENCES}

Abu Tabeekh, S. and S. Mudhar (2016). The effect of color light and stocking density on some biochemical traits of broilers and layers. Research in Zoology. 6(2): 21-28.

Astuti, P., B. Al Fajar, M. Mauludin, A. Hana, C. Mona Airin, S. Sarmin, and S. Harimurt (2015). Corticosterone levels, heterophil/lymphocyte ratios and growth rates in LohmannIndian River chickens raised under monochromatic blue light. Int. J. Poult. Sci. 14(12): 639-643.

Barbosa, V.C., A. Gaspar, L.F.L. Calixto, and T.S.P. Agostinho (2011). Stability of the pigmentation of egg yolks enriched with omega-3 and carophyll stored at room temperature and under refrigeration. R. Bras. Zootec. 40(7): 1540-1544.

Boehringer Manheim GmbH Biochemica (1995). Methods of biochemical analysis and food analysis; Manheim (Germany). 26-28 p

Borille R., R.G. Garcia, A.F.B. Royer, M.R. Santana, S. Colet, I.A. Naas, F.R. Caldara, I.C.L. Almeida Paz, E.S. Rosa, and V.A.R. Castilho (2013). The use of light-emitting diodes (LED) in commercial layer production. Braz. J. Poult. Sci. 15(2): 135-140.

Borille, R., R.G. Garcia, I.A. Nääs, R.F. Caldara, and M.R. Santana (2015). Monochromatic lightemitting diode (LED) source in layers hens during the second production cycle. Rev. Bras. Eng. Agríc. Ambient. 19(9): 877-881.
Cao, J., W.Z. Liu Wang, D. Xie, L. Jia, and Y. Chen (2008). Green and blue monochromatic lights promote growth and development of broilers via stimulating testosterone secretion and myofiber growth. J. Appl. Poult. Res. 17: 211-218.

Er, D., Z. Wang, J. Cao, and Y. Chen (2007). Effect of monochromatic light on the egg quality of laying hens. J. Appl. Poult. Res. 16(4): 605-612.

Firouzi, S., H.H. Nazarpak, H. Habibi, S.S. Jalali, Y. Nabizadeh, F. Rezaee, R. Ardali, and M. Marzban (2014). Effects of color lights on performance, immune response and hematological indices of broilers. J. World Poult. Res. 4(2): 52-55.

Gongruttananun, N. (2011). Influence of red light on reproductive performance, eggshell ultrastructure, and eye morphology in Thainative hens. Poult. Sci. 90: 2855-2863.

Groot, R.M.K. (2018). Optimal light spectrum to laying hens. M.Sc. thesis (unpublished). Dept. of Animal Environment and Health, Swedish University of Agricultural Sciences. Uppsala.

Guevara, B.D.M.I., P.S.I. Pech, B.R.I. Zamora, S.L.F.I. Navarrete, and S.H.F. Magaña (2015). Performance of broilers reared under monochromatic light emitting diode supplemental lighting. Braz. J. Poult. Sci. 17(4): 553-558.

Hassan, M.R., S. Sultana, H.S. Choe, and K.S. Ryu (2013). Effect of monochromatic and combined light colour on performance, blood parameters, ovarian morphology and reproductive hormones in laying hens. ITAL.J.ANIM.SCI. 12(3): 359364.

Hassan, M. R., S. Sultana, S.H. Choe, and K.S. Ryu (2014). Effect of combinations of monochromatic led light color on the performance and behavior of laying hens. J. Poult. Sci. 51: 321-326.

Hassan, M.R., S. Sultana, S.H. Kim, and K.S. Ryu (2016). Effect of monochromatic and combined LED light colours on performance, blood characteristics, meat fatty acid composition and 
immunity of broiler chicks. Europ. Poult. Sci. 80:1-17.

Hesham, M., A. El Shereen, and S. Enas (2018). Impact of different light colors in behavior, welfare parameters and growth performance of Fayoumi broiler chickens strain. J.Hellenetic Vet. Med. Soc. 69(2): 951-958.

Huber-Eicher, B., A. Suter, and P. Spring-Stähli (2013). Effects of colored light-emitting diode illumination on behavior and performance of laying hens. Poult. Sci. 92: 869-873

Ibrahim, S.A., S.Z. El Kholya, A.H. El-Far, and U.E. Mahrous (2012). Influence of lighting color on behavior, productive traits and blood parameters of Japanese quail (Coturnix Coturnix Japonica). World Academy of Science, Engineering and Technology. 67: 1234-1244.

Kim, M.J., H.C. Choi, and O.S. Suh (2010). A study of different sources and wavelengths of light on laying egg characteristics in laying hens. Korean J. Poult. Sci. 37: 383-388.

Ke, Y.Y., W.J. Liu, Z.X. Wang, and Y.X. Chen (2011). Effects of monochromatic light on quality properties and antioxidation of meat in broilers. Poult. Sci. 90: 2632-2637.

Leigh, M.B., T.B. McFadden, L. Schumacher, and J.D. Firman, 2017. Efficacy of various wavelengths of monochromatic light emitting diode illumination on growth and performance of broiler chickens. Int. J. Poult. Sci. 16: 475-480.

Lewis, P.D., L. Caston, and S. Leeson (2007). Green light during rearing does not significantly affect the performance of egg-type pullets in the laying phase. Poult. Sci. 86: 739-743.

Li, D., L. Zhang, M. Yang, H. Yin, H. Xu, J.S. Trask, D.G. Smith, Z. Zhang, and Q. Zhu (2014). The effect of monochromatic light-emitting diode light on reproductive traits of laying hens. J. Appl. Poult. Res. 23 :367-375.

Li, D.Y., N. Wu, J.B. Tu, Y.D. Hu, M.Y. Yang, H.D. Yin, B.L. Chen, H.L. Xu, Y.F. Yao and Q. Zhu (2015). Expression patterns of melatonin receptors in chicken ovarian follicles affected by monochromatic light Genet. Mol. Res. 14 (3): 10072-10080.

Li, G., B. Li, Y. Zhao, Z. Shi, Y. Liu, and W. Zheng, (2019). Layer pullet preferences for light colors of light-emitting diodes . Animal. 13(6): 12451251.

Long, H., Y. Zhao, T, Wang, H, Xin, and Z. Ning (2014). Comparative evaluation of light-emitting diode (LED) vs. fluorescent (FL) lighting in commercial aviary hen houses. An ASABE CSBE/ASABE Joint Meeting Presentation; Quebec, Canada, 13-16 July. Paper Number: 141893157. p. 383.
McDonald, P., R.A. Edwards, J.F.D. Greenhalgh, L.A. Morgan Sinclair, and R.G. Wilkinson (2011). Animal Nutrition. Prentice Hall; 7 edition (1600). London (England). $714 \mathrm{p}$

Moreno, J.A. J. Díaz-Gómez, C. Nogareda, E. Angulo, G. Sandmann, M. Portero-Otin, J.C.E. Serrano, R.M. Twyman, T. Capell, C. Zhu and P. Christou (2016). The distribution of carotenoids in hens fed on biofortified maize is influenced by feed composition, absorption, resource allocation and storage. Scientific Reports. 6:35346

Mudhar A.S. Abu Tabeekh (2016). The effect of color light and stocking density on some enzymes and hormones of broilers and layers. Mirror of Research in Veterinary Sciences and Animals (MRVSA). 5 (1): 25-37.

Olanrewaju, H.A., J.L. Purswell, S.D. Collier, and S.L. Branton (2015). Effects of color temperatures (Kelvin) of LED bulbs on blood physiological variables of broilers grown to heavy weights. Poult. Sci. 94: 1721-1728. http://dx.doi.org/10.3382/ps/pev139.

Ortiz, D., A. Ponrajan, J.P. Bonnet, T. Rocheford, and M. Ferruzzi (2018). Carotenoids stability during dry-milling, storage and extrusion processing of biofortified maize genotypes. J. Agric. Food Chem. 66(18): 4683-4691.

Prescott, N.B., and C.M. Wathes (1999). Spectral sensitivity of domestic fowl (Gallus g. domesticus). Br. Poult. Sci. 40: 332-339.

Riber, A.B. (2015). Effects of color of light on preferences, performance, and welfare in broilers. Poult. Sci. 94: 1767-1775.

Rozenboim, I., E. Zilberman, and G. Gvaryahu (1998). New monochromatic light source for laying hens. Poult. Sci. 77: 1695-1698.

Rozenboim, I., I. Biran, Z. Uni, and O. Halevy (1999). The involvement of monochromatic light in growth, development and endocrine parameters of broilers. Poult. Sci. 78:135-138.

Rozenboim, I., I. Biran, Y. Chaiseha, S. Yahav, A. Rosenstrauch, D. Sklan, and O. Halevy (2014). The effect of green and blue monochromatic light combination on broiler growth and development. Poult. Sci. 83: 842-845.

Ruot, B., D. Breulle', F. Rambourdın, G. Bayle, P. Capitan and C. Obled (2000). Synthesis rate of plasma albumin is a good indicator of liver albumin synthesis in sepsis. Am. J. Physiol. Endocrinol Metab. 279: E244-E251.

SAS (2000). SAS (Statistical Analysis System). User's guide: Statistics. SAS Institute Inc. Cary, NC.

Schieber A., and R. Carle (2005). Occurrence of carotenoid cis-isomers in food: Technological, 
analytical, and nutritional implications. Trends Food Sci. Technol. 16:416-422.

Smith, W.K. (1978). The amino acid requirement of laying hen: Models for calculation 1 . physiological background. World Poult. Sci. J. 34: 81-96.

Speer, B.L. (2015). Current Therapy in Avian Medicine and Surgery. 1st Edition, Hardcover ISBN: 9781455746712. eBook ISBN: 9780323243674.

Sultana, S., M. R. Hassan, H. S. Choe, K. S. Ryu. (2013). Effect of monochromatic and mix LED light colour and age on the behaviour and fear responses of broiler chicken. Avian. Biolog. Research. 6: 207-214.

Svobodová, J., E. Tůmová, E. Popelářová, and D. Chodová (2015). Effect of light colour on egg production and egg contamination. Czech J. Anim. Sci. 60: 550-556.
Thaxton, J.P., and S. Puvadolpirod (2000). Model of physiological stress in chickens 5. Quantitative Evaluation. Poult. Sci. 79: 391-395.

$\mathrm{Wu}, \mathrm{G}$. (2017). Principles of Animal Nutrition. CRC Press, 1st Edition, $772 \mathrm{p}$

Yang, Y.F., J.S. Jiang, J.M. Pan, Y.B. Ying, X.S. Wang, M.L. Zhang, M.S. Lu, and X.H. Chen (2016). The relationship of spectral sensitivity with growth and reproductive response in avian breeders (Gallus gallus). Scientific Reports, 6:19291, DOI: 10.1038/srep19291.

Zhang, X., X.U. Hongqing, L.I. Monan, X.U. Hongmei and L.I.U.Muqing (2017). Effects of different monochromatic light of LED on the growth performance of Jinmao broilers and egg laying performance of Jinmao breeders. J.Sci. Tech.in Lighting. 41: 143-147. 